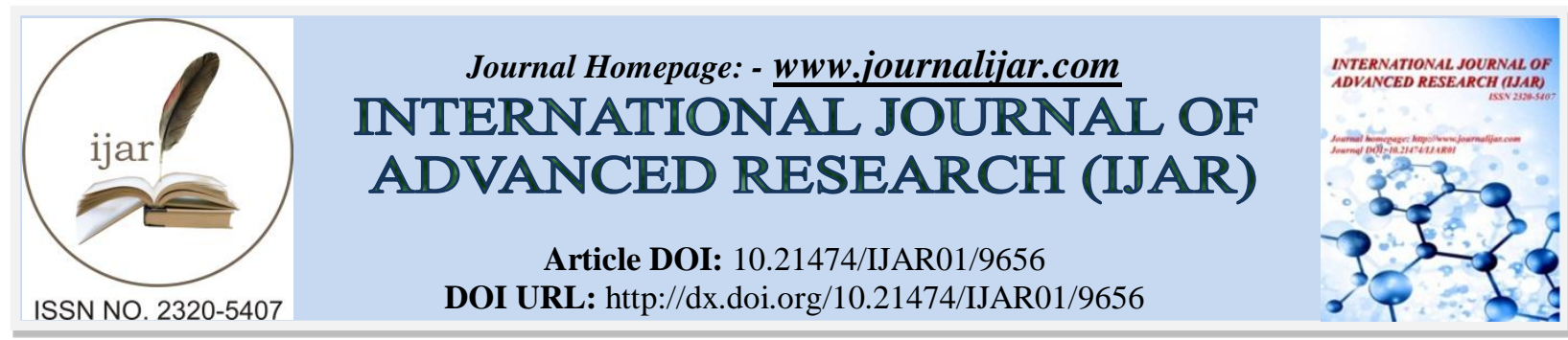

RESEARCH ARTICLE

\title{
HARMONICA SCALPEL VERSUS MILLIGAN MORGAN TECHNIQUE WITH ELECTRO CAUTERY FOR HAEMORRHOIDECTOMY.
}

Bahaa Saleh Abdalnby ${ }^{1}$, Mustafa Adham Ismael ${ }^{1}$ and Hussein Jasim Dadoosh Al-janabi ${ }^{2}$

1. M.B.Ch.B, M.Sc (Radiology) A radiologist at Al-Nuaman Teaching Hospital.

2. M.B.Ch.B, DS A general surgeon at Al-Nuaman Teaching Hospital.

\section{Manuscript Info}

Manuscript History

Received: 04 July 2019

Final Accepted: 06 August 2019

Published: September 2019

Key words:-

Haemorrhoidectomy, Milligan Morgan,

Harmonica scalpel.

\section{Abstract}

Background: The hemorrhoids is a quite common disease that is usually treated by surgery (stage 3 and 4 ) depending on the grade of the disease at presentation with some role for conservative treatment when presented early (stage 1 and 2). The open conventional haemorrhoidectomy by Milligan Morgan supported by electro cautery was used, many new techniques established among these is Harmonica scalpel.

Materials and method: 302 patients in stage 3 and 4 haemorrhoids involved in this study in the time period from January 2016 to December 2018. Harmonica scalpel used for the surgical treatment of 152 patients, and 150 patients treated by conventional haemorrhoidectomy.

A comparison was made between these two methods regarding operation time, postoperative pain, post-operative bleeding, analgesics, hospitalization, time to return to normal activity and post-operative complications.

Results: The average time for operation was $15 \pm 5$ minutes with postoperative hospitalization 6 hours for Harmonica scalpel, for Milligan Morgan the average time for operation was $25 \pm 7$ minutes with postoperative hospitalization 24 hours. Peri-operative bleeding was negligible for Harmonica scalpel and was significant for conventional haemorrhoidectomy. Post-operative bleeding was negligible in patients submitted to HS and was significant in patients underwent MM, analgesics were needed for 3 days after HS technique and 10 days for MM surgery.

Conclusion: HS haemorrhoidectomy is preferred technique to be used in grade 3 and 4 haemorrhoids with shorter operation time, less intraoperative \& post-operative bleeding, less post-operative pain \& less post-operative complications as compared with the conventional Milligan Morgan's procedure. 


\section{Introduction:-}

Haemorrhoids is a quite common disease mainly after age of 40 year. According to the degree of prolapse it can be classified into 4 grades, grade one and two (early) usually treated conservatively while grade three and four (late) are beyond conservative treatment and usually requires some form of surgical intervention $(1,2)$.

The most common surgical approach for those late stages is the conventional surgery whether open technique Milligan Morgan- or the closed technique -Ferguson Technique (3, 4).

Milligan Morgan (MM) procedure is not free from complications like post-operative pain, bleeding and anal stenosis $(5,6)$, that's why Harmonica Scalpel (HS) was developed as an alternative to the conventional method (7).

Unlike other electrosurgical devices this is an ultrasonic cutting and coagulation device which causes minimal lateral tissue damage. The HS causes 1-3 mm lateral tissue injury which is the half caused by electrosurgical device, less fumes, no neuromuscular stimulation and more localised impact $(7,8)$.

This study aimed at making a comparison between haemorrhoidectomy done by HS and MM methods.

\section{Materials and methods:-}

The study covered 302 patients with grade 3 and grade 4 haemorrhoids. At Al-Rahma and Al-Mukhtar private hospitals, 152 patients were operated upon by HS and 150 patients were operated upon by MM technique at AlNuaman teaching hospital in the time period from January 2016 to December 2018.

A comparison between haemorrhoidectomy done by HS and MM with regard to the following parameters: operation time, post-operative pain, post-operative bleeding, analgesics, hospitalization, time to return to normal activity and post-operative complications. Bleeding, anal stenosis, urinary retention and abscess formation.

All patients were prepared by one enema done at night before surgery then admitted at morning of same day of operation.

Spinal and caudal anaesthesia with intravenous sedation was done for all patients, they were positioned in lithotomy position, two fingers anal dilatation was performed. For MM v-shaped incision was made for every single haemorrhoid using the surgical scissors with dissection of the pedicle off the underlying anal sphincter then transfixed by suture of No.1 vicryl then cutting of the haemorrhoidal mass. An intra-anal packing and dressing to control bleeding was done.

Haemorrhoidectomy with HS was based on the same principles after positioning the patient in lithotomy position, then the haemorrhoidal mass was dissected using the harmonica scalpel with the aid of an artery forceps to control the pedicle then a No.1 vicryl suture is used to transfix the pedicle which was cut away with HS then simple dressing is used to control bleeding.

Patients without complications were discharged from hospital six hours after HS operation and one day after MM operation.

Operation time was the period between making the incision and transfixing the haemorrhoidal pedicle with a suture. Analgesia in form of paracetamol ampule $1 \mathrm{gm}$ twice daily and Acupan ampule $20 \mathrm{mg}$ I.M twice daily needed postoperatively for both groups. Analgesia used for 3 and 10 days for HS and MM respectively.

\section{Results:-}

Mean age of patients was $30 \pm 5.2$ years for those who submitted for HS and $36 \pm 4.7$ years for patients underwent MM. The average time for HS operation was $15 \pm 5$ minutes and $25 \pm 7$ minutes for MM. The post-operative hospitalization was six hours for HS and 24 hours for MM. There was a significance difference $(\mathrm{P}=0.002)$ in time period needed to return to normal activity, it was 8-10 days for patients underwent HS and 18-20 days for patients exposed to MM (table-1).

Table 1:-Some characteristics of patients operated upon

\begin{tabular}{|l|c|c|c|}
\hline Parameters & Milligan Morgan & Harmonica Scalpel & P-value \\
\hline
\end{tabular}




\begin{tabular}{|l|c|c|c|}
\hline & $\mathrm{n}=150$ & $\mathrm{n}=152$ & \\
\hline Age (year) & $36 \pm 4.7$ & $30 \pm 5.2$ & 0.92 \\
\hline Operation time (minute) & $25 \pm 7$ & $15 \pm 5$ & 0.001 \\
\hline Mean hospitalization time (hr) & 24 & 6 & 0.004 \\
\hline Time to return to normal activity (day) & $18-20$ & $8-10$ & 0.002 \\
\hline
\end{tabular}

Table-2 revealed that post-operative bleeding was $4.2 \%$ in MM operation which was double that of HS operation $2.1 \%$, although this difference was not significant $(\mathrm{P}=0.31)$. Complications such as anal abscess, anal stenosis, and recurrence recorded in $\mathrm{MM}$ methods but not in $\mathrm{HS}$ technique.

Table 2:-Comparison of post-operative complication in Milligan Morgan and Harmonica Scalpel

\begin{tabular}{|l|c|c|c|}
\hline Parameters & $\begin{array}{c}\text { Milligan Morgan } \\
\mathrm{n}=150\end{array}$ & $\begin{array}{c}\text { Harmonica Scalpel } \\
\mathrm{n}=152\end{array}$ & P-value \\
\hline Post-operative bleeding (\%) & 4.2 & 2.1 & 0.31 \\
\hline Urinary retention (\%) & 26.6 & 14.5 & 0.009 \\
\hline Anal abscess & 7 & 0 & --- \\
\hline Anal stenosis & 1.4 & 0 & --- \\
\hline Anal incontinence & 0 & 0 & --- \\
\hline Recurrence & 3 & 0 & --- \\
\hline
\end{tabular}

Table-3 showed that majority of patients with HS need analgesics for three days post-operatively while 10 days treatment with analgesia were needed for patients with $\mathrm{MM}$, this difference was highly significant $(\mathrm{P}=0.00001)$.

Table 3:-The need for post-operative analgesia in Milligan Morgan versus Harmonica Scalpel

\begin{tabular}{|l|c|c|c|}
\hline Post-operative analgesia & $\begin{array}{c}\text { Milligan Morgan } \\
\mathrm{n}=150\end{array}$ & $\begin{array}{c}\text { Harmonica Scalpel } \\
\mathrm{n}=152\end{array}$ & P-value \\
\hline for 3 days & 7 & 143 & 0.00001 \\
\hline for 10 days & 143 & 9 & \\
\hline
\end{tabular}

\section{Discussion:-}

It is accepted world widely that the golden standard treatment for haemorrhoids is the conventional haemorrhoidectomy whether open or close method.

Conventional haemorrhoidectomy for stage 3 and 4 haemorrhoids is a tedious procedure associated with a significant morbidity and a prolonged convalescence (9). Harmonica scalpel is relatively a new device used for cutting and coagulation of tissues in haemorrhoidectomy. The principle of action of this device is using an ultrasonic wave which coagulate and cut tissues without transferring a neuromuscular current with a minimal lateral effect (1-3 $\mathrm{mm}$ ) that's why it's widely used (4), and due to significantly reduced postoperative pain after Harmonic Scalpel hemorrhoidectomy compared with electrocautery controls (10).

Minimal intra-operative bleeding occurs in HS operation which allows better exposure and giving the surgeon a better view thus reducing the operative time with minimal tissue damage, hence faster wound healing and less postoperative morbidity and less post-operative pain (4). This explain why patients in this study with HS type of operation have less risk of post-operative bleeding and need analgesia for only 3 days in contrast to MM surgery where they had more chance of bleeding and need longer period of analgesia.

The electro-cautery used with MM has the disadvantage of damaging the surrounding mucosa and transferring the current, furthermore it doesn't achieve sufficient vascular coagulation leading to inadequate exposure and a prolonged operation time. Sometimes the surgeon is in need to make some deep stiches to stop bleeding which may result in anal stenosis, loss of workforce and post-operative pain. In the current study anal stenosis occur only in patients treated by MM.

We found that haemorrhoidectomy done by HS has a shorter operation time $15 \pm 5$ minutes as compared to MM $25 \pm 7$ minutes with less post-operative bleeding $2.1 \%$ for HS \& $4.2 \%$ for MM. Thiyagarajan and Bhatnagar study showed that the time required for harmonic scalpel hemorrhoidectomy was in average $15.37 \pm 2.4$ minutes. While the time 
required for Milligan Morgan hemorrhoidectomy in an average was 35.6 \pm 4.7 minutes the difference was statistically significant (11).

Urinary retention was reported in 26.4\% for MM \& 14.2 for HS. The post-operative hospitalization was 6 hours for HS \& 24 hours for MM which is again lower for HS group.

In our study anal abscess and anal stenosis were recorded as a complication in MM but they weren't recorded in HS. Anal incontinence was not recorded in either group this was similar to Lim study in 2016 who also state that no anal incontinence was reported in his study (12).

Previous study has demonstrated that the incidence of residual haemorrhoid is 3.5\% and 5\% for $\mathrm{HS}$ and MM respectively $(13,14)$.

One year follow up revealed 3\% recurrence for MM but no one patient recorded with recurrence for HS, nevertheless longer follow up and larger sample study would be needed to reach a solid conclusion (15).

As stated in the previous randomized studies the pain is felt with maximal intensity in the first 24 hours and declines later on (15). In our study the patients needed post-operative analgesia for 3 days and 10 days for HS \& MM respectively.

The mean time to return to normal activity was 8-10 days and 18-20 days for HS \& MM respectively. Muzi et al. in 2007 report fast wound healing, a quick return to work and reduced postoperative pain (14).

We conclude from this study that HS haemorrhoidectomy is preferred method to deal with grade 3 \& 4 haemorrhoids with shorter operation time, less intra-operative \& post-operative bleeding, less post-operative pain \& less post-operative complications as compared with the conventional Milligan Morgan's procedure.

\section{References:-}

1. La Torre F, Nicolai AP, (2004). Clinical use of micronized purified flavonoid fraction for treatment of symptoms after hemorrhoidectomy: results of a randomized, controlled, clinical trial. Dis Colon Rectum, 47(5):704-10

2. Tjandra JJ, Chan MK, (2007). Systematic review on the procedure for prolapse and hemorrhoids (stapled hemorrhoidopexy). Dis Colon Rectum, 50(6): 878-92

3. Fergusen JA, Heaton J R, (1959). Closed haemorrhoidectomy. Dis Colon Rectum, 2(2): 176-179.

4. Khanna R, Khanna S, Bahadani S, Singh S, Khanna AK, (2010).

5. Comparison of Ligasure haemorrhoidectomy with conventional Fergusens haemorrhoidectomy. Indian J surg, 72(4): 294-297.

6. Sanchez C, Chinn BT, (2011). Hemorrhoids. Clin Colon Rectal Surg, 24(1): 5.

7. Kuehn HG, Gebbensleben O, Hilger Y, Rohde H, (2009). Relationship between anal symptoms and anal findings. Int J Med Sci, 6(2): 77.

8. Abo-Hashem AA, Sarhan A, Aly AM, (2010). Harmonic scalpel compared with bipolar electro-cautery hemorrhoidectomy, a randomized controlled trial. Int J Surg, 8(3): 2437.

9. Voutilainen PE, Haglund $\mathrm{CH},(2000)$. Ultrasonically activated shears in thyroidectomies, a randomized trial. Ann Surg, 231(3): 322-28.

10. Chen JS, You JF, (2010). Current status of surgical treatment for haemorrhoids. Systematic review and metaanalysis. Chang Gung Med J, 33(5): 488-500.

11. Armstrong DN1, Ambroze WL, Schertzer ME, Orangio GR, (2001). Harmonic Scalpel vs. electrocautery hemorrhoidectomy: a prospective evaluation. Dis Colon Rectum, 44(4): 558-64.

12. Thiyagarajan A, Bhatnagar S, (2017). Comparative study of management of grade III hemorrhoids by Harmonic Scalpel technique versus conventional surgical technique (Milligan Morgan method). Int Surg J, 4(9): 3007-14

13. Lim DR, Cho DH, Lee JH, Moon JH, (2016). Comparison of a hemorrhoidectomy with ultrasonic scalpel versus a conventional hemorrhoidectomy. Ann Coloproctol, 32(3): 111-16

14. Engel AF, Eijspouts QA, (2000). Haemorrhoidectomy: painful choice. Lancet, 355(9222): 2253-54.

15. Muzi MJ, Milito G, Nigro C, Cadeddu F, Andriole F, Amabile D, et al., (2007). Randomized clinical trial of ligature and conventional diathermy haemorrhoidectomy. Br J Surg, 94(8): 937-42.

16. Kwork SY, Chung CC, Tsui KK, Li MK, (2005). A double-blind randomized trial comparing ligasure and harmonic scalpel haemorrhoidectomy. Dis colon Rectum, 48(2): 344-48. 